\title{
RELACIONAMENTO INTERPESSOAL PROFESSOR-ALUNO NA EDUCAÇÃO FÍSICA
}

\author{
Maria Trevizan Baccarelli \\ Larissa Ruella \\ Larissa Galatti \\ Carlos Silvestre
}

\section{Resumo}

O presente trabalho aborda o relacionamento interpessoal professor-aluno na Educação Física, partindo do pressuposto de que os conteúdos da Educação Física (jogo, esporte, luta, ginástica, atividades rítmicas e expressivas), transcendem aos aspectos motores, envolvendo outros aspectos relacionados ao ser humano integral, tal qual o cognitivo, afetivo e o social. A metodologia utilizada foi a pesquisa bibliográfica em artigos científicos e livros sobre comunicação e relacionamento interpessoal e, especificamente, na área de Educação Física, tratando sobre relacionamento interpessoal, processo ensino-aprendizagem e relação professor-aluno. Dentre as bibliografias citadas notou-se que a relação interpessoal professor-aluno é um importante veículo para proporcionar um adequado ambiente de ensino, vivência e aprendizagem. O relacionamento interpessoal é muito evidente principalmente nas aulas de Educação Física, pois esta disciplina permite maior liberdade de expressões e vontades. Concluíse que a comunicação interpessoal através de palavras, sinais do corpo e paralinguístico são fatores essenciais no processo ensino-aprendizagem.

\section{Palavras-Chave}

Educação Física; Relacionamento interpessoal professor-aluno; Processo de ensino, Vivência e aprendizado.

\section{INTERPERSONAL RELATIONSHIP PROFESSOR-PUPIL IN THE PHYSICAL EDUCATION}

Maria Trevizan Baccarelli

Larissa Ruella

Larissa Galatti

Carlos Silvestre

\begin{abstract}
This present work, has its main objective to study about the interpersonal relationship teacher-student in the Physical Education. It is assumed that Physical Education contents (games, sports, fights, gymnastics, rhythmic and expressive activities), tied with the motor aspects, go beyond this point, involving other aspects related to the integral human being relationship, such as the cognitive, affective and the social ones. The methodology applied was done through bibliographical research in scientific articles and books on communication and interpersonal relationship, teach and learning processes, and the relationship between the professor and student. Amongst all cited bibliographies it was noticed that the interpersonal relations teacher-student is an important vehicle to provide an appropriate learning environment, and learning experiences. The interpersonal relationship is very evident mainly in the lesson of Physical Education, therefore this disciplines allows to greater liberty of speech and wills. It is concluded that the
\end{abstract}

Conexões: revista da Faculdade de Educação Física da UNICAMP, Campinas, v. 8, n. 2, p. 19-32, maio/ago. 2010. 
interpersonal communication through words, signals of the body and tune of voice are essential in the process teach-learning.

\section{Key-Words}

Physical Education; Interpersonal relationship teacher-student; Teaching-learning process. 


\section{INTRODUÇÃO}

O presente trabalho tem como objetivo estudar a respeito do relacionamento interpessoal professor-aluno na Educação Física. Para isso foi necessário conceituar relacionamento interpessoal, visualizando o processo de ensino, vivência e aprendizagem. Assim, apresenta-se estudos recentes relacionados à produção científica sobre relacionamento interpessoal envolvendo professor-aluno na Educação Física.

O problema encontrado foi identificar, na literatura, estudos que tratem do relacionamento interpessoal entre professores e alunos e os seus indicativos sobre a influência da comunicação no processo de ensino, vivência e aprendizagem, surgindo então os questionamentos: qual a relação entre o professor e o aluno? Será que esta interfere na comunicação e aprendizagem do aluno?

Entende-se que os conteúdos da Educação Física, jogos, esportes, lutas, ginásticas, atividades rítmicas e expressivas (BRASIL, 2000), vinculados aos aspectos motores, vão além destes, envolvendo outros fatores relacionados ao ser humano integral, tal qual o cognitivo, afetivo e o social. O processo de ensino, vivência e aprendizagem, entretanto, não se dá de forma espontânea, mas por intencionalidades do professor na interação com o aluno, como mediador da informação, ganhando destaque as relações interpessoais. Nelas há envolvimento de diferentes ordens, ressaltando principalmente entre professor e aluno, tal, relacionamento interpessoal.

Com o passar dos anos e o surgimento constante de novas ferramentas tecnológicas, o contato entre professor e aluno pode ser monitorado através de um computador ou por outra tecnologia ainda mais inovadora. Pressupõe-se que nas aulas de Educação Física na escola a figura do professor é muito importante e necessária, pois envolve o elo afetivo, que inclui os relacionamentos interpessoais e permite, através das atividades corporais esportivas, culturais e cooperativas, experiências positivas e negativas que ensinam a conviver harmoniosamente uns com os outros (CASTAGNOLI, 2009). Mas antes mesmo que isso tudo ocorra espera-se que tanto os educadores quanto toda a sociedade saiba da importância desta relação, pois ainda supõe-se que o relacionamento interpessoal (contato face a face) do professor de Educação Física e do aluno passa despercebido durante o ciclo escolar.

O estudo se justifica pela ausência de disciplinas específicas na grade curricular de cursos de Educação Física sobre comunicação e relacionamento interpessoal e ao consultar a bibliografia, assim como pela averiguada a carência de publicações na temática, que motivou ainda mais a realização da tal pesquisa. 
Ademais, as aulas de Educação Física envolvem o estar fora da sala, que permite uma relação mais informal, onde muitas vezes os alunos sentem maior liberdade de expressão verbal ou não, envolvendo principalmente o movimento corporal, onde poderá transparecer muito mais seus sentimentos do que dizer, permitindo assim, expor características da sua personalidade muitas vezes camufladas no dia-a-dia. Neste contexto enfatiza-se que o professor deveria estar melhor preparado para acolher os alunos em suas demandas.

Este artigo está dividido em dois momentos, o primeiro abordando o significado de comunicação e relacionamento interpessoal e o segundo contendo estes dois conceitos focados na área de Educação Física e no processo de ensino-aprendizagem.

\section{MÉTODO}

Procurou-se, numa perspectiva qualitativa, tratar o objeto de estudo a partir de uma pesquisa bibliográfica em livros e artigos científicos. Segundo Traldi; Dias (2006, p. 43):

Pesquisa Bibliográfica - este tipo de pesquisa busca explicar um problema com base em contribuições teóricas publicadas em documentos (livros, revistas, jornais, etc.) e não por intermédio de relatos de pessoas ou experimentos. Pode ser realizada de forma independente ou estar inserida (levantamento bibliográfico) nos demais tipos de pesquisas.

A pesquisa bibliográfica foi realizada em duas dimensões:

- Sobre comunicação e relacionamento interpessoal, englobando diferentes áreas do conhecimento;

- Na especificidade da área de Educação Física, tratando sobre relacionamento interpessoal, processo ensino-aprendizagem e relação professor-aluno.

A partir desses elementos, os dados recolhidos em fontes bibliográficas impressas e digitais foram analisados a partir de uma matriz de análise de conteúdo, por meio de categorias que permitiram reconhecer o objeto da pesquisa.

\section{RELACIONAMENTO E COMUNICAÇÃO INTERPESSOAL}

Desde o nascimento, o ser humano passa por processos de interação social, gerando assim a comunicação, da simples até a mais complexa. Esta que é realizada e influenciada através do relacionamento com outras pessoas. E todo o processo de comunicação tem o compreender e o se fazer

Conexões: revista da Faculdade de Educação Física da UNICAMP, Campinas, v. 8, n. 2, p. 19-32, maio/ago. 2010.

ISSN: 1983-9030. 
compreendido, porém todo ser humano possui sua individualidade, culturas e etnias diferentes e experiências diversificadas, nesse sentido verifica-se que a comunicação não é objetiva. (SILVA, 2007).

Segundo Capitanio (2003) a comunicação é um processo: uma pessoa emite uma mensagem para outra(s). A pessoa que envia codifica os pensamentos em uma mensagem, a mensagem é canalizada geralmente por palavras para o receptor. $\mathrm{O}$ receptor decodifica a mensagem, pensa sobre e responde internamente. Para que a comunicação seja eficaz a mensagem deve ser interpretada. Para Franco (2000) a capacidade de ouvir é fundamental para que o processo de comunicação flua.

Muitas mensagens que transmitimos são entendidas não só pelo que falamos, mas também por como agimos. Segundo Franco (2000) e Silva (2007), apenas 7\% dos pensamentos são transmitidos por palavras, 38\% sinais paralinguísticos (voz: entonação e velocidade, que transcendem a própria fala) e 55 \% sinais do corpo (fisionomia, olhar, expressão corporal). A escrita, a fala, as expressões faciais, a audição e o tato são formas de comunicação amplamente utilizadas, conscientemente ou não.

Isso enfatiza ainda mais a importância do tal estudo, pesquisas indicam que 55\% da comunicação são através dos sinais do corpo, ponto muito forte quando tratamos da Educação Física, onde espera-se que deve ser trabalhada com os futuros profissionais.

De acordo com Weinberg; Gould (2001) a comunicação ocorre de duas formas básicas: interpessoal e intrapessoal. A comunicação intrapessoal é a comunicação que o indivíduo tem consigo mesmo, de extrema importância e que ajuda a moldar ou prever o modo como se age ou se atua consigo mesmo, afetando a motivação e o comportamento. Ressaltando neste, à comunicação interpessoal. A pessoa que envia a mensagem pretende afetar a resposta de uma determinada pessoa ou pessoas. A mensagem pode ser recebida pela pessoa para quem ela foi planejada, por pessoas para as quais ela não foi planejada ou ambos. Às vezes a mensagem chega distorcida e a resposta pretendida pela pessoa que a envia não é transmitida. A comunicação interpessoal envolve a comunicação não verbal, essencial para partilhar e receber informações.

Barnlund (1978) define a comunicação interpessoal como aquela que é desenvolvida em situações sociais relativamente informais em que as pessoas, em encontros face a face sustentam uma interação, concentrada através da permuta recíproca de pistas verbais e não verbais. Littlejohn (1978) afirma que relacionamento é um padrão de interação entre duas pessoas, baseado em suas percepções recíprocas.

Conexões: revista da Faculdade de Educação Física da UNICAMP, Campinas, v. 8, n. 2, p. 19-32, maio/ago. 2010. ISSN: 1983-9030. 
Segundo Macedo (2008) a comunicação interpessoal face a face é considerada a mais completa de todas, visto que propicia uma troca instantânea que vão muito além de palavras: gestos, expressões faciais, tom de voz etc.

A Educação Física, por sua especificidade de tratar os conteúdos relacionados ao corpo em sua integridade e por sua tradição prática, favorece a comunicação em sua complexidade e propicia relacionamento professor-aluno em maior profundidade, por isso esses temas serão tratados neste artigo.

\section{PROCESSO DE APRENDIZAGEM E O RELACIONAMENTO INTERPESSOAL PROFESSOR-ALUNO}

Os Parâmetros Curriculares Nacionais (PCN’s) foram consolidados para apontar metas de qualidade que ajudem o aluno a enfrentar o mundo atual como cidadão participativo, reflexivo e autônomo, conhecedor de seus direitos e deveres. Os PCN's objetivam que é o desenvolvimento do conhecimento de cada ser e o sentimento de confiança em suas capacidades afetiva, física, cognitiva, ética, estética e inter-relação pessoal. E também que é a utilização de diferentes linguagens, seja verbal, gráfica ou corporal, para explanar suas idéias ou responder a qualquer situação de comunicação. (BRASIL, 2000, grifo nosso). Assim como os parâmetros para o Ensino Fundamental (descritos acima) objetivam basicamente a comunicação, o relacionamento, os PCN’s da Educação Física para o Ensino Médio, classificam a disciplina na área de "Linguagem, Códigos e suas Tecnologias", tendo como competência desta área: analisar, interpretar e aplicar os recursos específicos das linguagens. (BRASIL, 1999).

Consideram-se estes objetivos relevantes para a pesquisa em questão, tendo em vista que a Educação Física é um Componente Curricular da Educação Básica (Infantil, Fundamental e Médio), e para que os alunos possam tornar-se cidadãos autônomos, participativos, inclusos e integrados, devem saber comunicar-se e relacionar-se. A comunicação, a linguagem e o relacionamento interpessoal no ambiente escolar, são impreterivelmente necessários para possíveis transformações sociais, afetivas e motoras. E para fazer jus a classificação da Educação Física como um componente curricular, deve-se agir como tal e não somente como uma profissão regulamentada.

Muito se questionou quanto à influência do professor sobre o aprendizado do aluno. Hoje, acredita-se que são as ações do professor durante as aulas que influenciam no aprendizado do aluno, ao contrário do que se pensava antes, onde a personalidade do professor agia sobre o aprendizado. Desta forma atual, poderá 
ser proporcionado ao aluno vivenciar relacionamentos diferentes, onde fatores sociais, culturais e políticos influenciaram diretamente nesse processo de aprendizagem. É importante ressaltar que, deve-se mensurar o quanto o aluno aprendeu e não o quanto o professor ensinou. (SANTOS, 2001).

A relação professor-aluno é baseada em interesses e intenções, tem como intuito principal o aprendizado, de onde acaba gerando a educação, esta que é uma das fontes mais importantes do desenvolvimento comportamental e agregação de valores de qualquer cidadão. Sendo assim o papel do professor é de facilitador da aprendizagem, não detentor de todo o saber, devendo estar aberto a novas experiências, a compreensão dos sentimentos e problemas de seus alunos. (SILVA, 2005).

Devido às questões colocadas, verifica-se a aplicação da abordagem construtivista nas aulas de Educação Física, pois se pode considerar o repertório motor já possuído, a valorização da cultura e o contexto da realidade de cada aluno, onde o mesmo poderá contribuir com a aula e interagir sem constrangimentos ou medos, podendo expressar-se. E ainda há um importante intermediador do aprendizado, o jogo, onde há um espaço lúdico e por meio deste o aluno assimila o conteúdo e interage com o outro e com o meio, enquanto se diverte, sem frustrações.

Arantes (1989, p. 33) identifica que "A relação professor-aluno é um modo de interação ou encontro profundo que se estabelece entre pessoas. Reflete uma atitude de objetivo bem definido que permite o encontro de educador e educando." Santos (2001) completa que há a interação com os colegas de classe, esta que também os auxiliará no processo de aprendizagem.

Arantes (1989) salienta ainda que, do professor são requeridas certas características de intenções e atitudes que contribuem para o crescimento pessoal e intelectual do aluno propiciando consistentemente para seu amadurecimento emocional e desenvolvimento pessoal, ou seja, esta interação tem que ser contínua.

De fato a interação deve ser contínua e intensa, onde o aluno mesmo após o término dos estudos, certamente se lembrará de algo que seu professor tenha lhe influenciado positivamente. Mas, infelizmente, da mesma forma que há influência positiva, há a negativa, que por muitas vezes pode ser mais lembrada do que os bons fatos ocorridos.

Zagury (1999) menciona que o professor ensina, os alunos aprendem, ou seja, aprender deveria ser

Conexões: revista da Faculdade de Educação Física da UNICAMP, Campinas, v. 8, n. 2, p. 19-32, maio/ago. 2010. 
considerado conseqüência inevitável do ensinar. No entanto, Cabral, Carvalho e Ramos (2004) vão além, quando dizem que nesse sentido pode-se dizer que o professor quebra a possibilidade de um relacionamento harmonioso entre ele e o aluno, e se este não se adapta ao controle, ele é considerado rebelde, indisciplinado, quando na verdade pode ser apenas uma forma de não aceitação de imposições estabelecidas pelo professor e pela escola. Há um distanciamento entre professor e aluno no que diz respeito a subjetividade, sendo que, muitas vezes, as relações são mecânicas, ritualistas e sem vida.

Estas atitudes, que certamente são vestígios de uma Educação Física Militarista, quando o conhecimento da teoria não era valorizado, necessitavam somente de um corpo saudável, pronto para lutar. Cabia aos alunos somente obedecer, sem questionar e, se o assim fizesse, seria considerado um rebelde. Ao contrário do que vivenciamos hoje durante as aulas, nas quais a liberdade de expressão é possível, mas não valorizada como deveria. (DARIDO; ANDRADE, 2005).

É necessário superar vestígios da Educação Física Militarista, onde havia somente atitudes relacionadas à exigência de performance, condicionamento a certas tarefas, obediência e ausência de voz ativa e abrir espaço a uma comunicação mais aberta e proposição de atividades que estimulem os alunos a pensar, a refletir, a solucionar problemas e não apenas repetir e reproduzir tarefas.

Relacionar-se quer dizer interagir um com o outro. Assim, o processo de ensino aprendizagem sai do âmbito tradicional e o professor passa a ensinar aprendendo. (CAPITANIO, 2003).

Castagnoli (2009) acredita que o relacionamento interpessoal na ambiente escolar, de acordo com a qualidade das experiências vivenciadas, é capaz de exercer significativa influência na formação integral do aluno, possibilitando reduzir a agressividade, melhorar a aprendizagem e a formação da personalidade, desenvolvendo suas potencialidades para o exercício consciente da cidadania. As dificuldades sociais e econômicas em nosso país, interferem de modo significativo no rendimento escolar, ocasionando consequentemente o aumento de evasão e repetência e colocando em risco a integridade física, psíquica e moral de todos os envolvidos no processo ensino-aprendizagem. Para que essas dificuldades de relacionamento sejam sanadas, Libâneo (1994) diz que o trabalho do professor deve ir além da transmissão de informações e questionamentos, o educador deve transmitir segurança aos alunos. Onde esses poderão, sem receio, expressar suas opiniões e pensamentos, podendo receber e dar suas respostas. A atuação docente nunca é unidirecional.

A escola e, neste caso, a Educação Física possui conteúdos a serem abordados, o que poderá ser melhor Conexões: revista da Faculdade de Educação Física da UNICAMP, Campinas, v. 8, n. 2, p. 19-32, maio/ago. 2010. ISSN: 1983-9030. 
desenvolvido por meio de um adequado relacionamento interpessoal. Além disso, a própria capacidade de relacionamento interpessoal dos alunos será desenvolvida a partir das atividades relacionadas aos conteúdos da Educação Física, o que pode ser melhorado com uma adequada comunicação professoraluno.

A interação é um processo delicado, com certas dificuldades e limitações, e esta é reconhecida por Ricoeur (1969 apud SANTOS, 2001, p. 72):

\begin{abstract}
Esta relação (professor-aluno) é difícil, sem dúvida das mais difíceis de ser exercida em nossa sociedade. É primeiramente uma relação assimétrica, em que a carga de competência e experiência dá licença, de parte do ensinante, ao exercício de um domínio que é muito fácil de consagrar nos meios de instituições hierárquicas e coercitivas. A tendência espontânea do ensinante é pensar que o ensinado não sabe nada, que aprender é passar da ignorância ao saber, e que esta passagem está em poder do mestre.
\end{abstract}

Seria pretensão de o educador lecionar esperando que não houvesse uma troca de informações. Espera-se estar sempre receptivos quanto a novas situações, lembrando que o processo de ensino aprendizagem nunca é unidirecional, não somente do professor para o aluno, mas também do aluno para o professor. $\mathrm{O}$ relacionamento interpessoal consiste nesta abertura, onde o professor está disposto a receber seus alunos em suas buscas e interpretar estes objetivos colocados pelos alunos. Podendo assim emergir uma forma mais parceira de comunicação professor-aluno.

Para Arantes (1989) a interação professor-aluno é fundamental para uma boa adaptação escolar, influenciando na atitude futura desse aluno, não só durante sua fase de aprendizagem, mas na sua relação com os sucessivos professores. O relacionamento interpessoal professor-aluno é fator preponderante na facilitação da aprendizagem.

A mesma influência é confirmada por Freire (1996, p. 66):

O professor autoritário, o professor licencioso, o professor competente, sério, o professor incompetente, irresponsável, o professor amoroso da vida e das gentes, o professor mal-amado, sempre com raiva do mundo e das pessoas, frio, burocrático, racionalista, nenhum desses passa pelos alunos sem deixar sua marca.

É de grandiosa importância a colocação de Freire, pois qualquer cidadão que tenha passado por algum nível escolar lembra-se do professor que mais the marcou, seja de forma positiva ou negativa.

Para enfatizar toda a real necessidade da interação professor-aluno, Darido (2005) coloca que nessa relação o diálogo deve ser contemplado, e que é de responsabilidade do professor, como mediador,

Conexões: revista da Faculdade de Educação Física da UNICAMP, Campinas, v. 8, n. 2, p. 19-32, maio/ago. 2010. 
promover um ambiente de reflexão, trocas e decisões superadoras das situações problemas e que o processo de ensino-aprendizagem depende dessa interação professor-aluno.

Arantes (1989) sugere três orientações básicas que devem estar presentes no trabalho do professor, em sua interação com os alunos. Ao invés de punir o comportamento destrutivo, estimular e incentivar o comportamento construtivo; ao invés de forçar o aluno, orientá-lo na execução das atividades escolares, ouvindo o que tem a dizer e evitar a formação de preconceitos, por meio da observação e do diálogo constantes que permitem ao professor constatar as mudanças que estão ocorrendo com o aluno e compreender o seu desenvolvimento.

Segundo Duarte (2004) há três condições facilitadoras para a aprendizagem, quando considerarmos a relação professor-aluno, são elas: congruência, consideração positiva ou aceitação e empatia. A congruência refere-se à autenticidade do professor, pois todos os sentimentos do aluno estão ao alcance do professor, totalmente perceptível, tornando essa relação direta e pessoal. A aceitação é acreditar que o ser humano é confiável, é acreditar que possui sua individualidade, é de se esperar que o professor não seja tão imparcial quanto um terapeuta e não tão afetivo quanto um parente próximo como um pai, mas que possa transmitir segurança e confiança ao aluno. A empatia é de extrema importância, pois é necessário ouvir e compreender o aluno. Deve-se aplicar uma escuta ativa para entendê-los.

Libâneo (1994) ressalta o discernimento necessário para separar professor do famoso tio, relacionamento interpessoal não é a afetividade do professor para com determinados alunos, nem de amor pelas crianças. A relação maternal e paternal deve se evitada, porque a escola não é a casa e a família, literalmente falando, e os alunos não são nossos sobrinhos e muito menos filhos.

Ao surgimento desta colocação verificou-se que de fato este tipo de relação não deve ser cultivada no ambiente escolar, pois o relacionamento interpessoal não agrega esse tipo de afetividade, e sim uma relação de trocas e interesses, autoridade e autonomia, e um contato face a face para facilitar o processo ensino-aprendizagem.

\section{DISCUSSÃO}

Dentre as bibliografias citadas notou-se que a relação interpessoal professor-aluno é um importante veículo para a aprendizagem e um importante fator de ordem e disciplina na aula. A comunicação não-

Conexões: revista da Faculdade de Educação Física da UNICAMP, Campinas, v. 8, n. 2, p. 19-32, maio/ago. 2010. ISSN: 1983-9030. 
verbal no processo de ensino-aprendizagem interfere de forma significativa, pois através da expressão facial do aluno o professor consegue analisar se está sendo compreendido. Cabe ao professor despertar a crença e interesse do ouvinte, e uma das formas é ser gentil e agradável, como exemplo, chamar os alunos pelo nome.

Não se pretende induzir a ligação professor-aluno ao afeto familiar, mas sim instigar o relacionamento interpessoal. E para que isso ocorra, o professor deverá estar bem preparado para colher os alunos em suas demandas afetivas, sociais e motoras.

A interação professor-aluno é uma relação de trocas e interesses, onde o professor é mediador da informação, esta que será geradora do conhecimento aos seus alunos. Conhecimento este que os levarão a conviver em sociedade, como cidadãos autônomos, participativos e tolerantes.

Para isso é fundamental que o professor de Educação Física conheça os tipos de comunicação citados anteriormente neste artigo, a partir de então começar a dialogar com os alunos, de forma simples e segura, e através de um feedback, interpretar suas expressões corporais tendo a certeza de que a mensagem e o objetivo da aula foram transmitidos e alcançados.

O relacionamento interpessoal é muito evidente principalmente nas aulas de Educação Física, pois esta disciplina permite maior liberdade de expressões e vontades.

A partir da bibliografia inferimos que o bom relacionamento interpessoal é de grande relevância nas aulas de Educação Física. Fica sugerido neste estudo a presença da disciplina comunicação e relacionamento interpessoal na grade curricular de Educação Física, que seria de grande importância para a formação de futuros profissionais.

\section{CONSIDERAÇÕES FINAIS}

O relacionamento interpessoal é a habilidade no trato com as pessoas independente do nível hierárquico, profissional ou social, influenciando positivamente e demonstrando respeito a individualidade, compreensão, convivência harmoniosa e tolerância a atritos interpessoais.

Devido aos fatos conclui-se que a comunicação interpessoal através de palavras, sinais do corpo e paralinguística são fatores essenciais no processo ensino-aprendizagem. A Educação Física por ser um

Conexões: revista da Faculdade de Educação Física da UNICAMP, Campinas, v. 8, n. 2, p. 19-32, maio/ago. 2010. 
componente curricular da Educação Básica tem o dever de preparar os alunos para atuar na sociedade capazes de comunicar-se e relacionar-se com os indivíduos desta, ou seja, a inter-relação conforme citado pelo próprio PCN's.

Esta pesquisa não tem a pretensão de esgotar o assunto. A pouca bibliografia encontrada sobre relacionamento interpessoal professor-aluno na Educação Física, dificultou em um resultado preciso para solucionar os problemas propostos. Mas, fica aqui a contribuição de duas futuras profissionais de Educação Física que é pretensiosa e deseja levar nas aulas de Educação Física um relacionamento mais harmonioso e sócio-afetivo em um mundo que se encontra hoje com tantas desigualdades sociais e estresses do dia-a-dia além das influências dos fatores externos.

\section{REFERENCIAS}

ARANTES, K. C. F. Breve reflexão sobre a relação professor-aluno no curso de educação física da Universidade Estadual de Londrina. Rev Fund Esporte Tur, Curitiba, v. 1, n. 2, p. 32-33, 1989.

BARNLUND, D. Comunicação interpessoal. In: LITTLEJOHN, S W. Fundamentos teóricos da comunicação humana. Rio de Janeiro: Zahar, 1978. Cap. 8.

BRASIL. Secretaria de Educação Fundamental. Parâmetros curriculares nacionais: educação física. 2. ed. Rio de Janeiro: DP\&A, 2000.

Secretaria do Ensino Médio. Parâmetros curriculares nacionais: ensino médio. Rio de Janeiro: DP\&A, 1999.

CABRAL, F. M. S.; CARVAlho, M. A. V.; RAMOS, R. M. Dificuldade no relacionamento professor/aluno: um desafio a superar. Paidéia, v. 14, n. 29, p. 327-335. 2004.

CAPITANIO, A. M. Relacionamento não verbal na Educação Física. Efdeportes: revista digital, Buenos Aires, ano 9, n. 64, sept. 2003. Disponível em: 〈http://www.efdeportes.com/efd64/noverb.htm〉. Acesso em: 24 ago. 2009.

CASTAGNOLI, C. A. Atividades esportivas, culturais e cooperativas como meio de superação no relacionamento interpessoal na escola. Disponível <http://www.diaadiaeducacao.pr.gov.br/portals/pde/arquivos/389-4.pdf>. Acesso em: 24 ago. 2009.

DARIDO, S. C.; ANDRADE, I. C. A. Educação Física na escola: implicações para a prática pedagógica. Rio de Janeiro: Guanabara Koogan, 2005. 
FRANCO, G. S. Psicologia no esporte e na atividade física: uma coletânea sobre a prática com qualidade. São Paulo: Manole, 2000.

FREIRE, P. Pedagogia da autonomia: saberes necessários a prática educativa. São Paulo: Paz e Terra, 1996.

KNAPP, M. L.; HALL, J. A. Comunicação não verbal na interação humana. São Paulo: JSN, 1999.

LIBÂNEO, J. C. Didática. São Paulo: Cortez, 1994.

LITTLEJOHN, S. W. Fundamentos teóricos da comunicação humana. Rio de Janeiro: Zahar, 1978.

MACÊDO, I. I. Comunicação. In: . Aspectos comportamentais da gestão de pessoas. 9. ed. São

Paulo: FGV, 2008. cap. 1.

RICOEUR, P. Reconstruir a universidade. Rev Paz e Terra, Rio de Janeiro, n. 9, 1969.

SANTOS, S. C. O processo de ensino-aprendizagem e a relação professor-aluno: aplicação dos "sete princípios para a boa prática na educação de ensino superior”. Cad Pesq Adm, v. 8, n.1, p. 69-82, 2001.

SILVA, J. P. S. A relação professor/aluno no processo de ensino e aprendizagem. Disponível em: <http://www.espacoacademico.com.br/052/52pc_silva.htm〉. Acesso em: 15 maio 2009.

SILVA, M. J. P. Comunicação tem remédio: a comunicação nas relações interpessoais em saúde. 5. ed. São Paulo: Loyola, 2007.

TRALDI, M. C.; DIAS, R. Monografia passo a passo. 5. ed. São Paulo: Alínea, 2006.

ZAGURY, T. Relação professor/aluno, disciplina e saber. Pátio: revista pedagógica, v. 2, n. 8, p. 9-12, 1999.

WEINBERG, R.; GOULD, D. Fundamentos da psicologia do esporte e do exercício. 2. ed. Porto Alegre: Artmed, 2001.

MARIA TREVIZAN BACCARELLI

FAJ - Faculdade de Jaguariúna

LARISSA RUELLA

FAJ - Faculdade de Jaguariúna

LARISSA RAFAELLA GALATTI

FAJ - Faculdade de Jaguariúna

CARLOS SILVESTRE

FAJ - Faculdade de Jaguariúna

Conexões: revista da Faculdade de Educação Física da UNICAMP, Campinas, v. 8, n. 2, p. 19-32, maio/ago. 2010. ISSN: 1983-9030. 


\section{Referencia do artigo}

\section{ABNT}

BACCARELLI, M. T. et al. Relacionamento interpessoal professor-aluno na educação física. Conexões, v. 8, n. 2, p. 19-32, 2010.

APA

BACCARELLI, M. T., RUELLA, L., GALATTI, L. R., SILVESTRE, C. (2010). Relacionamento interpessoal professor-aluno na educação física. Conexões, 8(2), 19-32.

\section{VANCOUVER}

BACCARELLI MT, RUELLA L, GALATTI LR, SILVESTRE C. Relacionamento interpessoal professor-aluno na educação física. Conexões, 2010; 8(2), 19-32.

Recebido em: mar./2010

Aceito para publicação em: jun./2010 